\title{
Hypoplastic Internal Carotid Artery Co- Presenting with Neurofibromatosis and Intracranial Masses
}

Arvin R. Wali ${ }^{1}$, David R. Santiago-Dieppa ${ }^{1}$, Jeffrey A. Steinberg ${ }^{1}$, Ali Alattar ${ }^{2}$, Vincent J. Cheung ${ }^{1}$, Royya Modir ${ }^{1}$, Alexander A. Khalessi ${ }^{1}$, J. Scott Pannell ${ }^{1}$

1. Department of Neurosurgery, University of California, San Diego 2. School of Medicine, University of California, San Diego

$\square$ Corresponding author: Arvin R.Wali, awali@ucsd.edu

Disclosures can be found in Additional Information at the end of the article

\section{Abstract}

Neurofibromatosis type 1 (NF1) is associated with systemic vascular disease, and it can also affect intracranial vasculature in a small percentage of patients. Very rarely, NF1 may copresent with hypoplasia of the internal carotid artery (ICA). Prior reports have documented NF1 with bilateral optic gliomas and a unilateral hypoplastic internal carotid artery; however, we report a case with the aforementioned findings in addition to a right-sided lentiform mass. This case report further suggests a common congenital pathway related to neurofibromin loss of function resulting in both nerve sheath tumors and cerebrovascular anomalies.

Categories: Neurology, Ophthalmology, Neurosurgery

Keywords: neurofibromatosis, optic glioma, hypoplastic internal carotid artery, lentiform mass, nerve sheath tumor, neurovascular abnormalities, intracranial vascular malformations, aplastic internal carotid artery, intracranial mass, neurofibromin

\section{Introduction}

Neurofibromin loss of function can result in systemic malignancies and vascular abnormalities [1]. Neurofibromatosis type 1 (NF1) affects one in three thousand people and can be associated with systemic vascular disease and malformations affecting the aortic, renal, and mesenteric arteries [2-3]. On the other hand, hypoplasia or aplasia of the internal carotid artery (ICA) not secondary to mass effect or compression is another very rare congenital anomaly that may lead to neurologic deficits or life threatening intracranial vascular abnormalities such as aneurysm formation [4-6].

Received 08/05/2016 Review began 08/15/2016 Review ended 08/16/2016 Published 08/26/2016

C) Copyright 2016

Wali et al. This is an open access article distributed under the terms of the Creative Commons Attribution License CC-BY 3.0., which permits unrestricted use, distribution, and reproduction in any medium, provided the original author and source are credited.
Case series have demonstrated NF1 with non-specific cerebrovascular dysplasia in as few as two percent of patients [7-9]. Moreover, in a case series reviewing NF1 and a hypoplastic ICA, the presence of optic gliomas was found in only a third of patients [10]. Here we discuss an extremely rare case that demonstrates a hypoplastic ICA, NF1, bilateral optic gliomas, and an additional lentiform mass. Informed consent was obtained from the patient for this study.

\section{Case Presentation}

Our patient is an 18-year-old female with known NF1 and bilateral optic gliomas who presented to the neurology department for evaluation of a hypoplastic left ICA demonstrated on a prior CT angiogram at an outside hospital. Given the rarity of a hypoplastic ICA in NF1 patients, workup was initiated with particular attention given to alternate etiologies such as 


\section{Cureus}

Moyamoya syndrome. The patient had a long-standing history of headaches, chronic leftgreater-than-right vision loss, intermittent vertigo, numbness, tingling, and pain. A physical exam confirmed her visual symptoms and demonstrated $4+/ 5$ right upper extremity weakness, hyporeflexia of the left triceps reflex, and diffuse café au lait spots. The patient underwent magnetic resonance imaging (MRI) and magnetic resonance angiography (MRA) imaging of the brain (Figures 1-3).

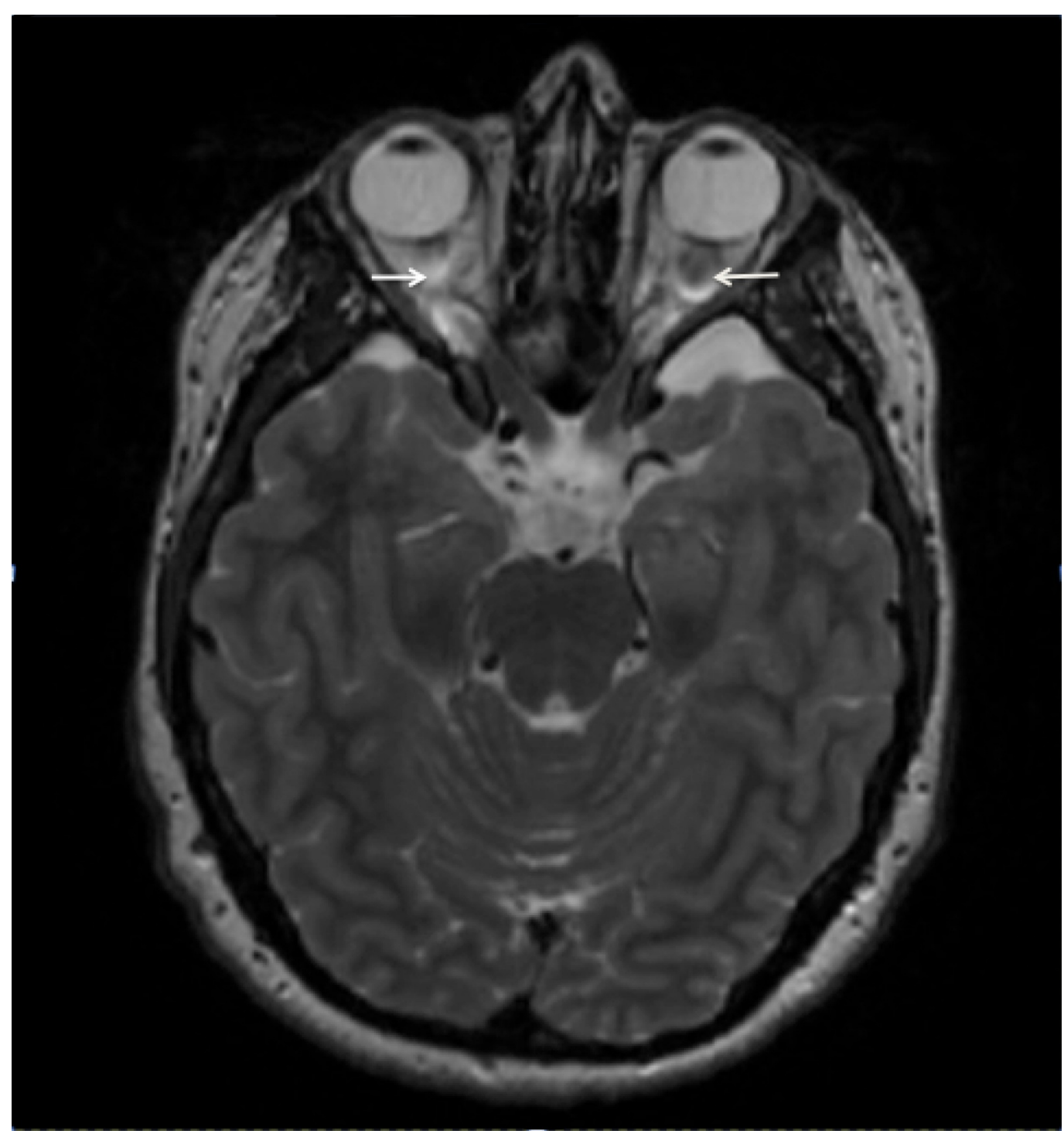

\section{FIGURE 1: T2 weighted axial MRI through the suprasellar} cistern

Bilateral optic nerve enlargement consistent with optic nerve gliomas. No significant mass effect on adjacent vasculature. 


\section{Cureus}

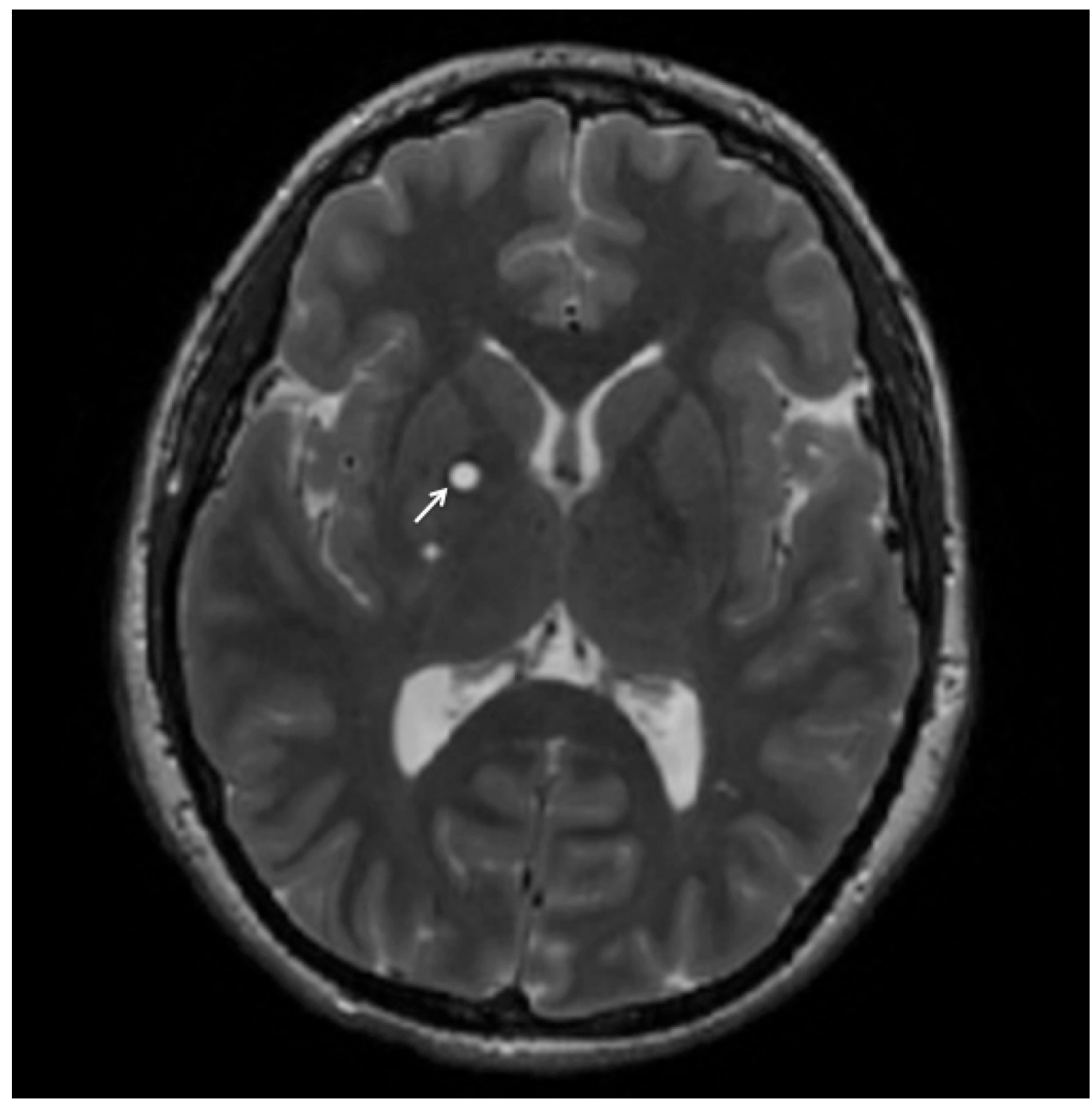

FIGURE 2: Axial T2 FLAIR MRI

Hyperintense lesions within the right lentiform nucleus concerning for glioma. 


\section{Cureus}

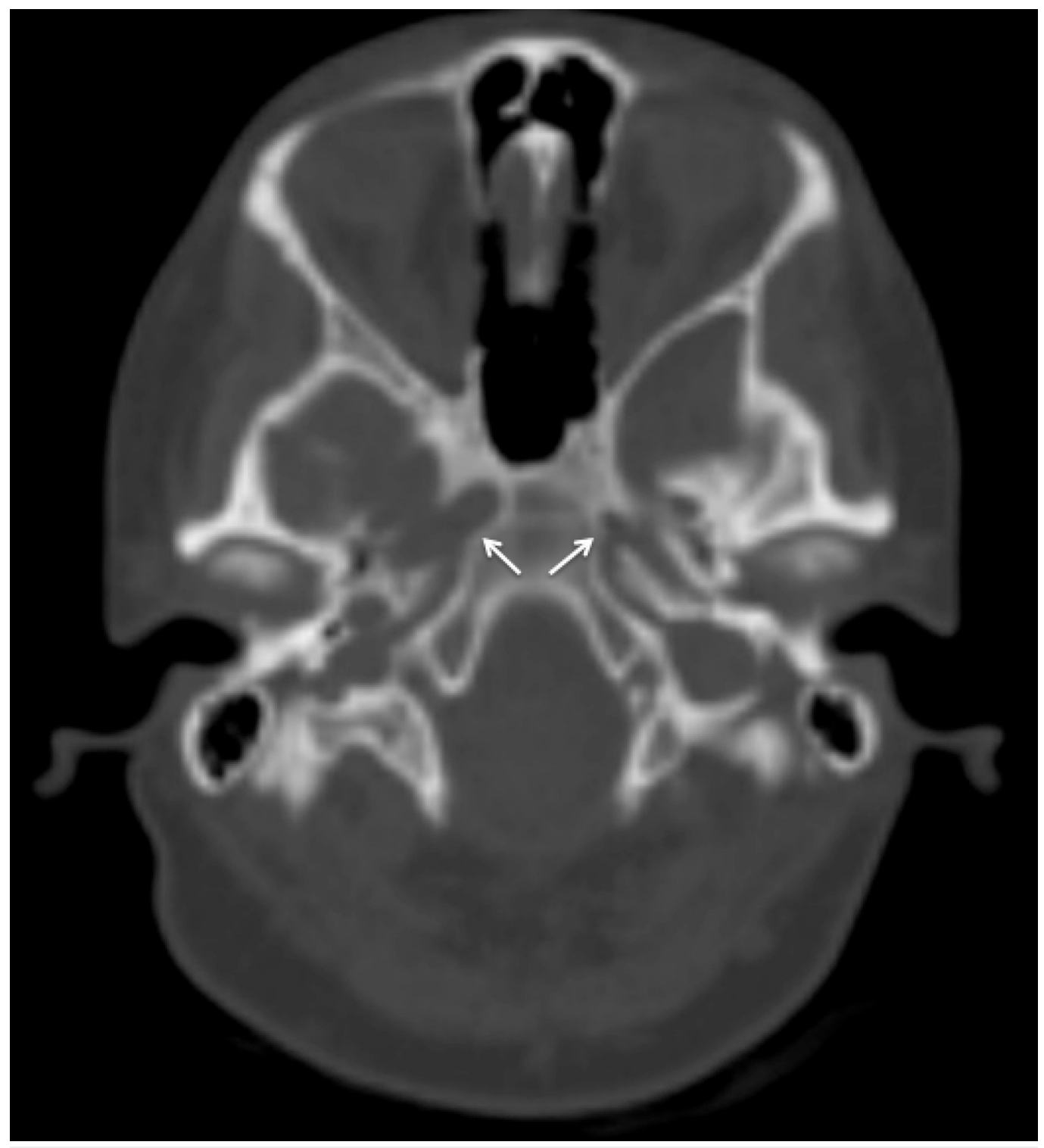

\section{FIGURE 3: Axial CT}

The right carotid canal and left hypoplastic carotid canal are demarcated by arrows.

The patient then underwent a diagnostic six-vessel cerebral angiogram (DCA) that demonstrated a complete left internal carotid occlusion distal to the branch of the ophthalmic artery. In addition, the entire left middle cerebral artery (MCA) and anterior cerebral artery (ACA) vascular territories were supplied by the right internal carotid via a robust anterior communicating artery (Figures 4-5). 


\section{Cureus}

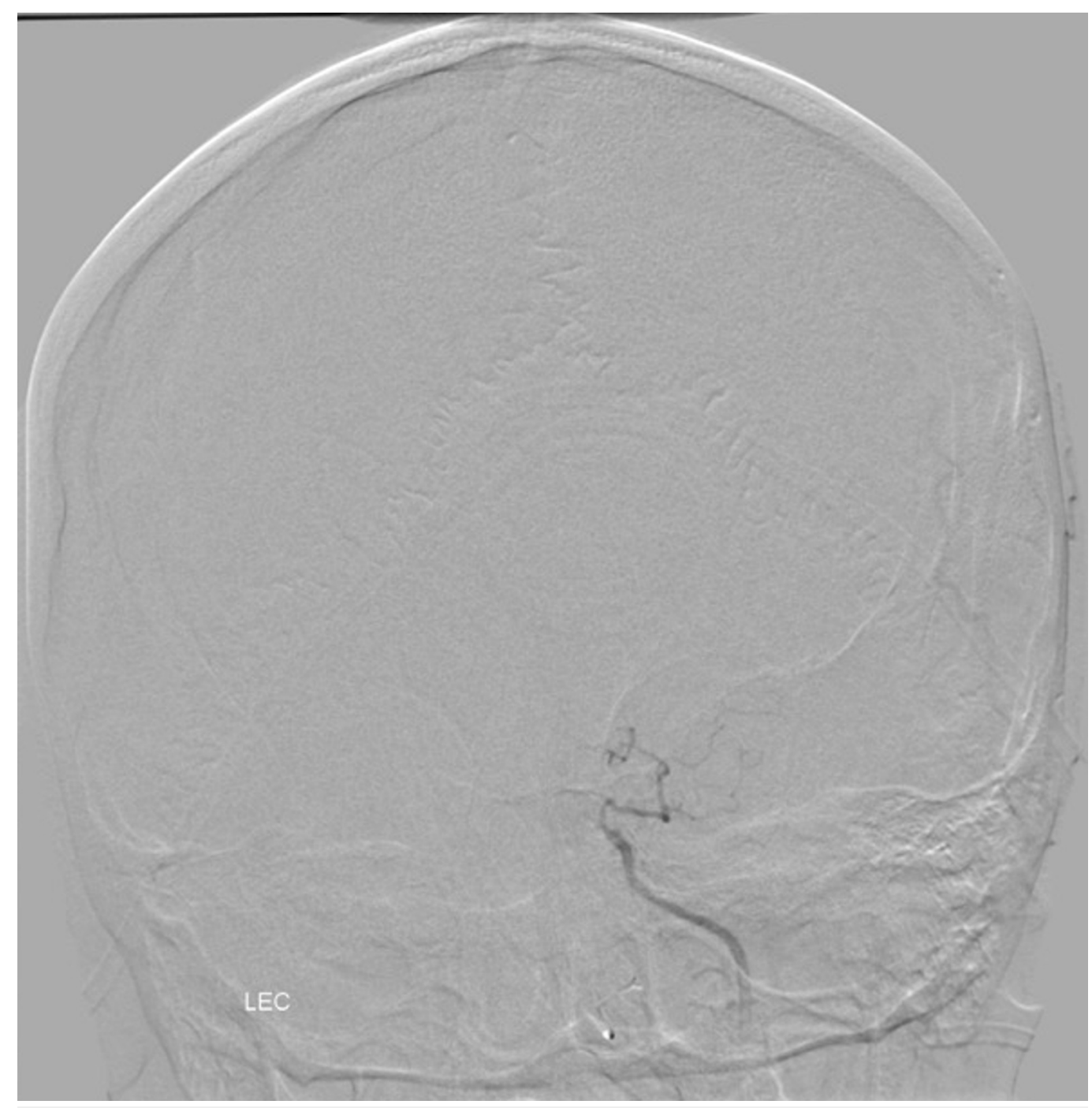

FIGURE 4: Posterior anterior (PA) angiogram of the anterior circulation

Left ICA demonstrates absence of the intracranial left ICA distal to ophthalmic branch consistent with hypoplasia of the left ICA. 


\section{Cureus}

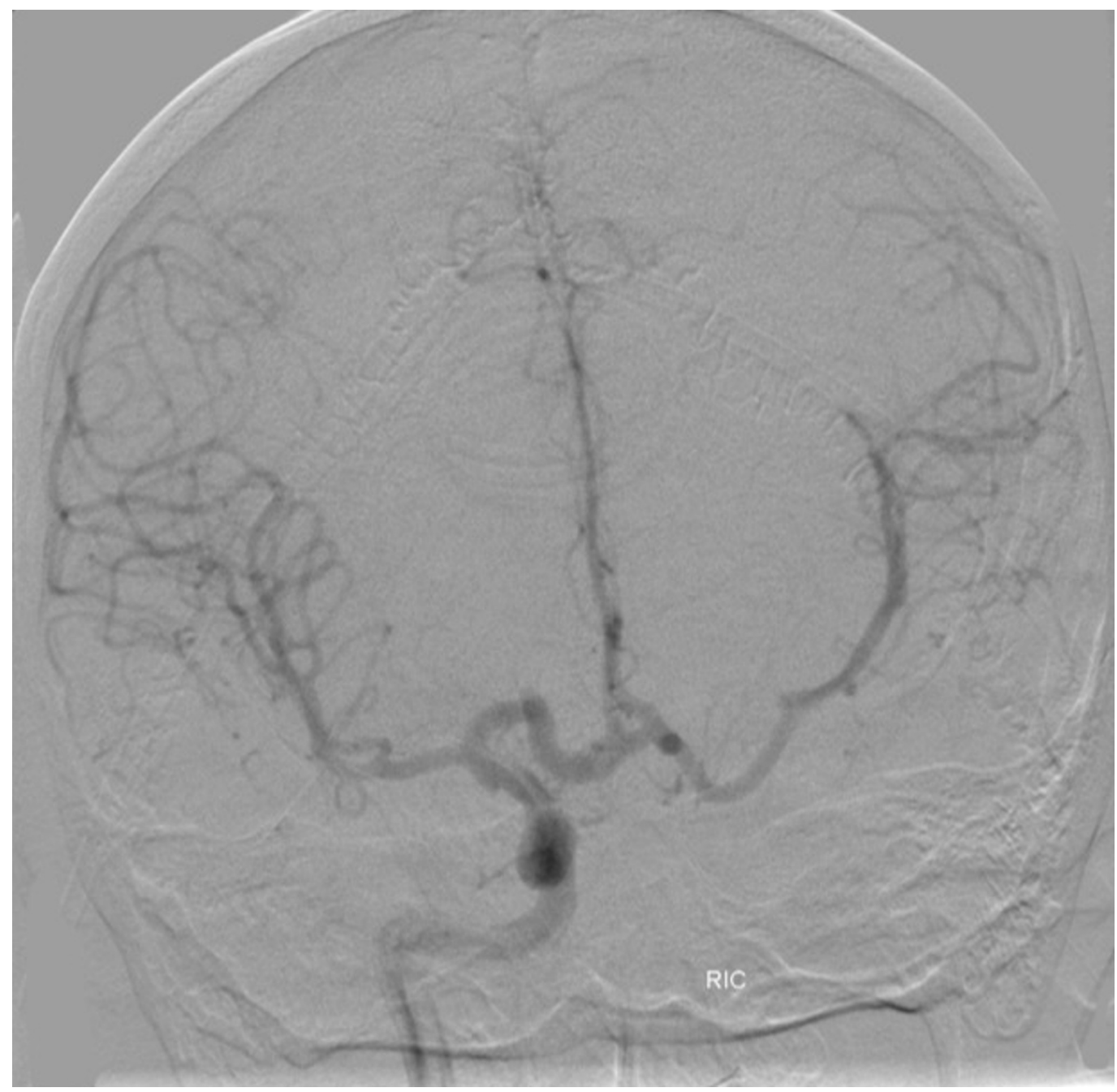

\section{FIGURE 5: PA angiogram of the anterior circulation}

Opacification of the bilateral middle cerebral and anterior cerebral arteries via enlarged anterior communicating artery.

The findings on the DCA excluded the diagnosis of Moyamoya syndrome and further characterized the complete occlusive disease of her left carotid artery with total perfusion of her anterior circulation via the right ICA through a very robust anterior communicating artery. Moreover, a computerized tomography (CT) of her head revealed hypoplasia of the internal carotid canal suggesting a long-standing congenital lesion. The additional lentiform mass was radiographically determined as not exerting mass effect and warranted scheduled surveillance imaging without further intervention. The patient has since been conservatively followed by the neurology service.

\section{Discussion}

This case demonstrates the presence of an intracranial mass in addition to a hypoplastic ICA and optic gliomas in an NF1 patient. This constellation of findings is extremely rare and further demonstrates a clinical example in which loss of function in neurofibromin results in both intracranial and systemic nerve sheath tumors and congenital vascular anomalies. This clinical presentation highlights the importance of further understanding the genetic pathways leading to neurologic tumors and vascular abnormalities. Moreover, this case suggests that 
further screening for intracranial or congenital malformations in the setting of neurofibromatosis is warranted to optimize management of vascular risk factors to minimize vascular neurologic injury.

\section{Conclusions}

Although neurofibromatosis is exceedingly rare, this disease can co-present with vascular manifestations, and this case report suggests the workup of congenital and acquired intracranial vascular disease for this patient population.

\section{Additional Information \\ Disclosures}

Human subjects: Consent was obtained by all participants in this study. Informed consent was obtained from the patient for this study. Conflicts of interest: In compliance with the ICMJE uniform disclosure form, all authors declare the following: Payment/services info: All authors have declared that no financial support was received from any organization for the submitted work. Financial relationships: All authors have declared that they have no financial relationships at present or within the previous three years with any organizations that might have an interest in the submitted work. Other relationships: All authors have declared that there are no other relationships or activities that could appear to have influenced the submitted work.

\section{References}

1. Li F, Munchhof AM, White HA, et al.: Neurofibromin is a novel regulator of RAS-induced signals in primary vascular smooth muscle cells. Hum Mol Genet. 2006, 15:1921-1930. 10.1093/hmg/ddl114

2. Oderich GS, Sullivan TM, Bower TC, et al.: Vascular abnormalities in patients with neurofibromatosis syndrome type I: clinical spectrum, management, and results. J Vasc Surg. 2007, 46:475-484. 10.1016/j.jvs.2007.03.055

3. Tedesco MA, Ratti G, Di Salvo G, et al.: Noninvasive evaluation of arterial abnormalities in young patients with neurofibromatosis type 1. Angiology. 2000, 51:733-741.

4. Taşar M, Yetişer S, Taşar A, Uğurel S, Gönül E, Sağlam M: Congenital absence or hypoplasia of the carotid artery: radioclinical issues. Am J Otolaryngol. 2004, 25:339-349.

5. Lee JH, Oh CW, Lee SH, Han DH: Aplasia of the internal carotid artery. Acta Neurochir (Wien). 2003, 145:117-25. 10.1007/s00701-002-1046-y

6. Claros P, Bandos R, Gilea I, Claros A, Capdevila A, Garcia Rodriguez J, Claros A: Major congenital anomalies of the internal carotid artery: agenesis, aplasia and hypoplasia. Int J Pediatr Otorhinolaryngol. 1999, 49:69-76.

7. Steel TR, Bentivoglio PB, Garrick R: Vascular neurofibromatosis affecting the internal carotid artery: a case report. Br J Neurosurg. 1994, 8:233-237.

8. Shuto T, Yamamoto I: Ocular ischaemia with hypoplasia of the internal carotid artery associated with neurofibromatosis type 1. Acta Neurochir (Wien). 2000, 142:353-354.

9. Cairns AG, North KN: Cerebrovascular dysplasia in neurofibromatosis type 1. J Neurol Neurosurg Psychiatry. 2008, 79:1165-1170. 10.1136/jnnp.2007.136457

10. Tomsick TA, Lukin RR, Chambers AA, Benton C: Neurofibromatosis and intracranial arterial occlusive disease. Neuroradiology. 1976, 11:229-234. 10.1007/BF00328378 